\title{
Acoustic deterrent devices to prevent pinniped depredation: efficiency, conservation concerns and possible solutions
}

\author{
Thomas Götz*, Vincent M. Janik \\ Sea Mammal Research Unit, Scottish Oceans Institute, University of St Andrews, East Sands, St Andrews, Fife KY16 8LB, UK
}

\begin{abstract}
Acoustic deterrent devices (ADDs) to prevent pinniped predation on fish farms and fisheries are widely used, but show highly varying success. Recently, ADDs have also been highlighted as a conservation concern due to their adverse impact on toothed whales. We review the available literature on the efficiency of commercial ADDs, evaluate the unintended impact on behaviour, communication and hearing of marine life, and suggest solutions based on psychophysiological predictions. The main problems associated with ADDs are a lack of long-term efficiency, introduction of substantial noise pollution to the marine environment and long-term effects on target and non-target species. Odontocetes have more sensitive hearing than pinnipeds at the frequencies where most ADDs operate, which may explain the reported large-scale habitat exclusion of odontocetes when ADDs are used. Furthermore, long-term exposure to ADDs may damage the hearing of marine mammals. Fish and invertebrates have less sensitive hearing than marine mammals and fewer efforts have been made to quantify the effects of noise on these taxa. Solutions can be found by decreasing sound exposure, exploiting neuronal reflex arcs associated with flight behaviour and making use of differences in species' hearing abilities to increase target specificity. To minimise adverse effects, environmental impact assessments should be carried out before deploying ADDs and only effective and target-specific devices should be used.
\end{abstract}

KEY WORDS: Acoustic deterrent device $\cdot$ ADD $\cdot$ Noise pollution $\cdot$ Predation $\cdot$ Seal $\cdot$ Hearing damage $\cdot$ Aquaculture $\cdot$ Fisheries $\cdot$ Temporary threshold shift $\cdot$ Permanent threshold shift

\section{INTRODUCTION}

Worldwide farming of marine and diadromous finfish species has experienced tremendous growth, with a 10-fold increase over the past 3 decades (Food and Agriculture Organization 2005). The resulting increase in potential food resources for other species in the marine environment could be expected to induce interactions with predatory species. Foraging models predict that air-breathing predators such as marine mammals will exploit food resources depending on their profitability and potential costs, with dive depths playing a major role (Thompson \& Fedak 2001). Without any predator-control methods, the costs, for example, for a seal of attacking a fish farm are low while the profitability is high. It is therefore not surprising that such interactions occur. Nevertheless, predation losses on fish farms in both North America and Europe have often been reported to be caused by only a few 'rogue' individuals (Scottish Salmon Growers Association 1990, Morris 1996). On some occasions, salmon growers reported that predation by harbour seals Phoca 
vitulina stopped after the specific individuals believed to be causing the problem were removed (Morris 1996). Similarly, reports from British Columbia showed that just a few male California sea lions Zalophus californianus reduced the annual steelhead trout Oncorhynchus mykiss run through the Ballard locks from 2500 to 200 in less than a decade (Fraker \& Mate 1999).

Predatory behaviour by seals around fish farms can cause a variety of economic as well as market-related risks for the owner (Nash et al. 2000), which has led to the development of several predator-control methods. These methods fall into one of the following categories: net modifications or additions of barrier nets, acoustic devices to deter seals, population control through lethal or non-lethal removals of seals, and aversive conditioning (Hawkins 1985, Würsig \& Gailey 2002, Quick et al. 2004). The most problematic of these is predator population control by lethal removal. These methods can be ecologically hazardous, particularly if the number of removed animals is underestimated (Ross 1988), are ethically controversial and their effectiveness is questionable (Pemberton \& Shaughnessy 1993), as newly arriving individuals can quickly replace removed animals (Ross 1988, Morris 1996). Furthermore, culling of higher-order predators can affect predation rates by other predators. Pinnipeds forage on predatory fish species around the net pen that could potentially feed on aquaculturally important species (Fraker \& Mate 1999).

Of all predator-control measures, acoustic deterrent devices (ADDs) have often been considered the most benign way of dealing with the problem. There are 2 basic assumptions of how acoustic deterrence may work. The first solution presents acoustic stimuli at a source level that exeeds the auditory pain threshold, with the idea being that animals would avoid such stimuli, and the second relies on the acoustic stimulus itself being aversive without causing pain. Over the past 2 decades, a variety of acoustic devices have been designed to reduce or stop predation by pinnipeds on finfish farms (Table 1). Low-power devices operating at source levels below $185 \mathrm{~dB}$ re $1 \mu \mathrm{Pa}$ have commonly been labelled as ADDs, while those operating at higher source levels are considered to be acoustic harassment devices (AHDs) (Reeves et al. 2001). However, suggesting an effect based on source level is problematic when reaction thresholds are poorly understood and vary depending on animal motivation (Götz \& Janik 2010). We will therefore refer to all devices as ADDs in this review, as deterrence is the ultimate goal when using them. Our review summa- rizes the current methodology in acoustic seal deterrence, investigates the problematic biological effects and their potential ecological consequences, and evaluates the potential of acoustics to control predation in general.

\section{HOW EFFECTIVE IS ACOUSTIC DETERRENCE?}

One of the first attempts to deter seals by the use of sound was carried out in the late 1970s with captive harbour seals and wild grey seals Halichoerus grypus around netted salmon (Anderson \& Hawkins 1978). The results were not promising: pure tones of unspecified source level had no effect and killer whale Orcinus orca calls and other recorded sounds (e.g. noise) seemed to be effective for a few successive trials, but aversive responses waned quickly.

Experiments with more powerful devices operating at high source levels were carried out by Mate \& Harvey (1987) and Mate et al. (1987). They used frequency-modulated pulses (8 to $20 \mathrm{kHz}$ ) of variable length at peak-to-peak (p-p) source levels of $\sim 187 \mathrm{~dB}$ re $1 \mu \mathrm{Pa}$ to deter harbour seals from salmon hatcheries for 4 successive years ( 1 to $32 \mathrm{~ms}$ long pulses at random intervals with an average of 2 per second). The paradigm applied was to deter seals by broadcasting sounds within the most sensitive frequency range of a seal. Reactions included seals turning away from the sound source and sometimes leaping out of the water before retreating quickly. In the 3 following years, the predation rate was substantially lower and only one individual seal was responsible for most of the damage. However, although the device seemed to prevent recruitment of new animals, in the fourth year the predation rate returned to its original level. Geiger \& Jeffries (1987) investigated the effect of an ADD on harbour seal predation on salmon fisheries using a device similar to that used by Mate \& Harvey (1987). While the ADD reduced predation in some fisheries, there were 2 sites where predation rates were higher when the ADD was switched on. In one fishery, predation increased over a $3 \mathrm{wk}$ period until it reached a much higher level than during control periods, which may indicate that the originally aversive sound had become a conditioned reinforcer, resulting in a 'dinner bell effect' (see also Jefferson \& Curry 1996).

The time until devices become ineffective varies between studies and study sites. Harvey \& Mate (1987) tried to establish an acoustic barrier after driving harbour seals from a haul-out in a bay where they forage on migrating salmon. Within the following week about one-third of the animals returned, which 


\begin{tabular}{|c|c|c|c|c|c|c|}
\hline 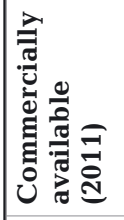 & 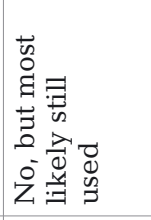 & 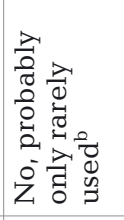 & 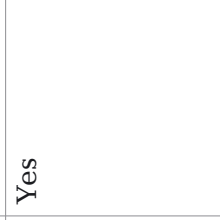 & $\underset{\nu}{\infty}$ & 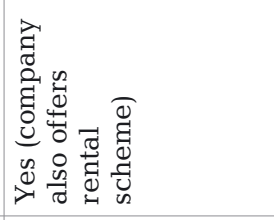 & $\underset{\nu}{\infty}$ \\
\hline 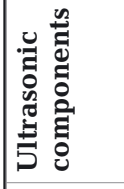 & 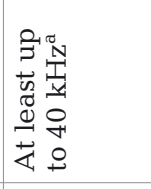 & & 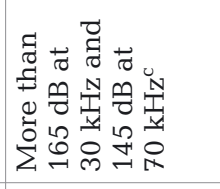 & 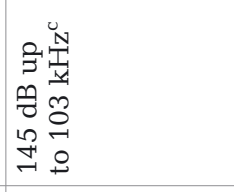 & 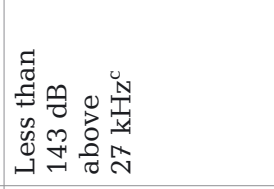 & 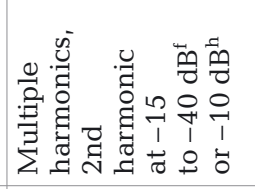 \\
\hline 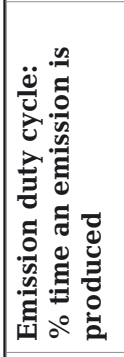 & 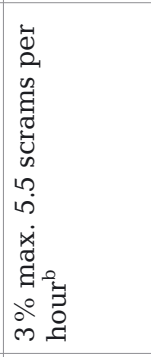 & 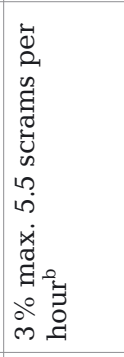 & 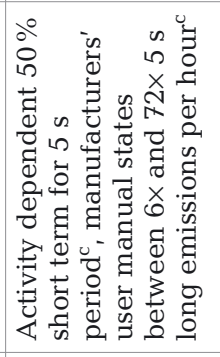 & 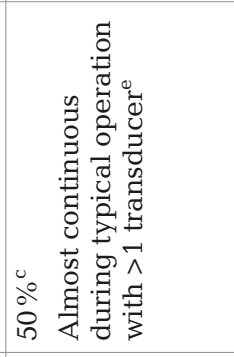 & 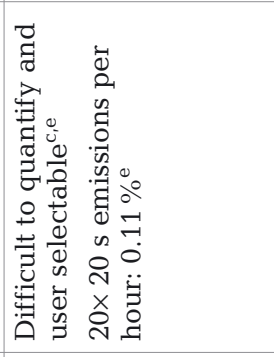 & 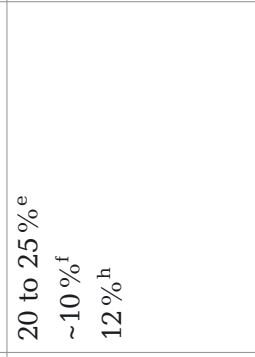 \\
\hline 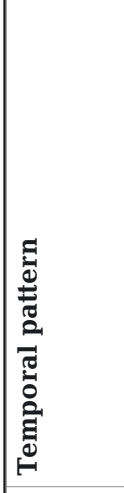 & 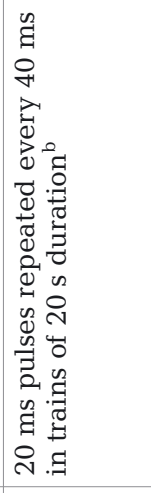 & 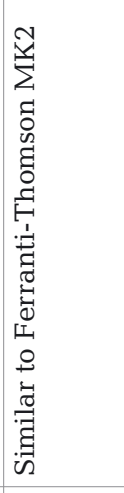 & 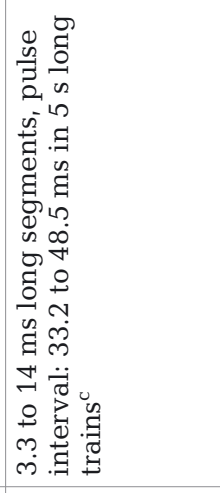 & 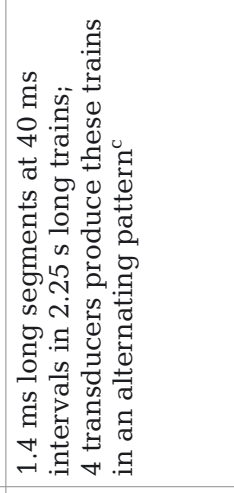 & 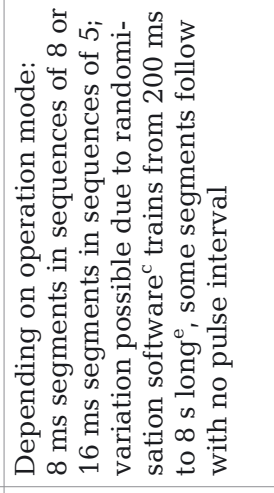 & 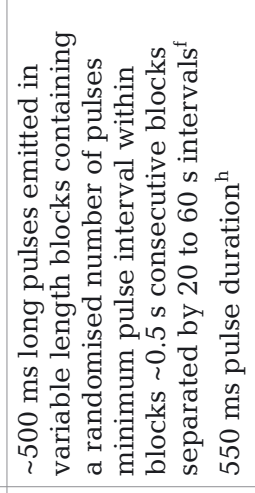 \\
\hline 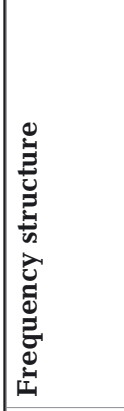 & 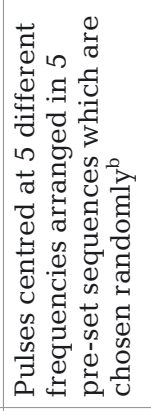 & 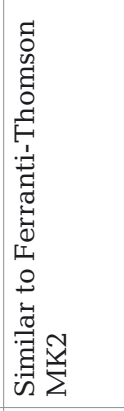 & 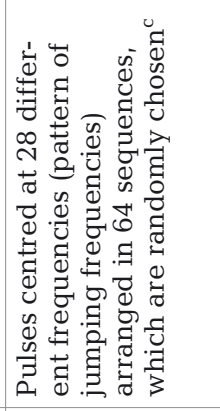 & 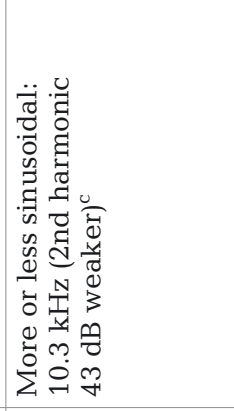 & 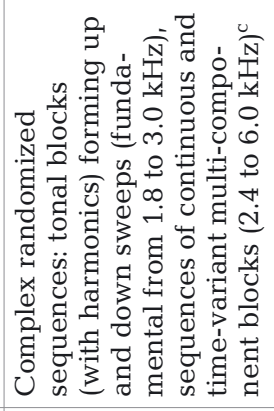 & 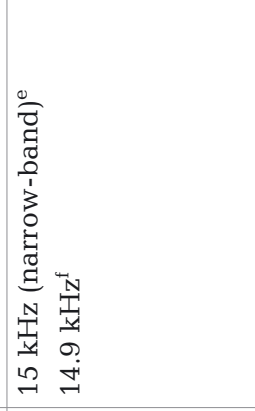 \\
\hline 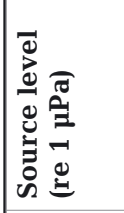 & 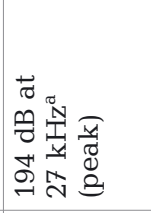 & 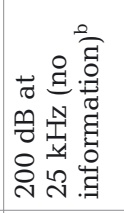 & 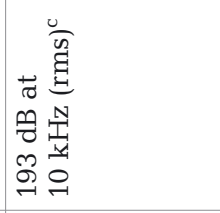 & 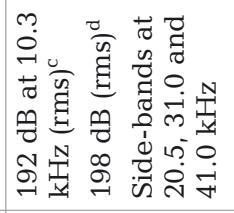 & 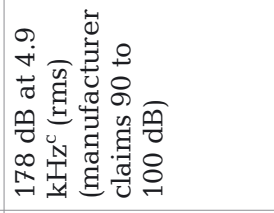 & 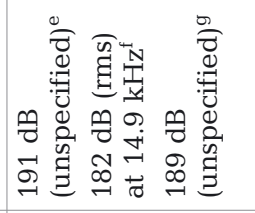 \\
\hline 通 & 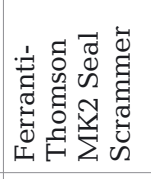 & 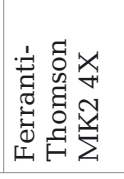 & 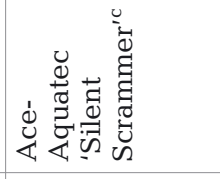 & 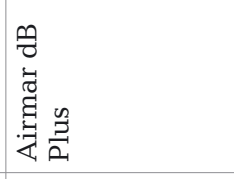 & 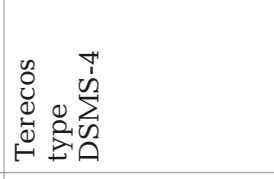 & 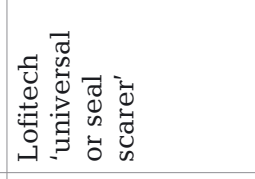 \\
\hline 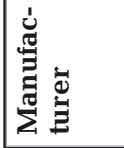 & 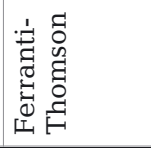 & & 离 & 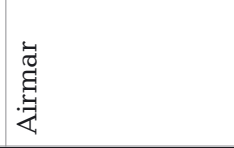 & 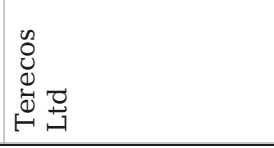 & 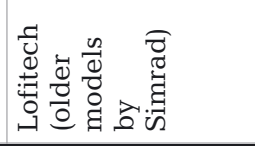 \\
\hline
\end{tabular}


may have been partly caused by intermittent failure of the deterrence device. In contrast, Rivinus (1987) reported that only in the third year after the introduction of a similar ADD did 1 or 2 harbour seals return to predate on a fish ladder. Kastelein et al. (2006a) successfully deterred captive harbour seals over a 2 mo period using $250 \mathrm{~ms}$ long pulses of 8 to $45 \mathrm{kHz}$ tones with harmonics. However, in this study there was no food associated with the location of the ADD.

Working on otariidae (eared seals), Akamatsu et al. (1996) investigated the reactions of captive Steller sea lions Eumetopias jubatus to sound while the animals were swimming in a pool or feeding on salmon attached to a net. They tested an iron drum (0.5 to $2 \mathrm{kHz}, 210 \mathrm{~dB}$ re $1 \mu \mathrm{Pa}$ ) and different playback sounds at a maximum source level (rms) of $165 \mathrm{~dB}$ re $1 \mu \mathrm{Pa}$. They found that killer whale calls yielded little effect, frequency-modulated sweeps ( 1 to $4 \mathrm{kHz}, 1 \mathrm{~s}$ duration, $1 \mathrm{~s}$ inter-stimulus interval) repelled juveniles and pure tones $(8 \mathrm{kHz}, 5 \mathrm{~s}$ duration, $5 \mathrm{~s}$ inter-stimulus interval) were successful in repelling all animals except adult males. Only the iron drum was able to deter adult males in the feeding trial, which might have been due to the high source levels of its sounds.

Only a few experiments have been carried out using commercially available ADDs under realistic settings. As Table 1 shows, the acoustic characteristics of devices that were sold commercially over the past years differ by manufacturer and model, which makes generalisations difficult. While some devices produce trains of brief pulses (Airmar, Ace-Aquatec), others produce longer, separated pulses (Lofitech) or emissions of more continuous noise (Terecos) (Table 1). Yurk \& Trites (2000) tested ADDs produced by Airmar and Ferranti-Thompson in an attempt to keep harbour seals from feeding on out-migrating salmon under a bridge. The Airmar dB Plus II deterrent device yielded a decrease of predation rate in 7 successive trials, but further trials were not carried out. The Ferranti-Thompson device was only tested once, yielding a decrease in the number of seals compared with the control trial on the following day, but seal numbers were still high compared with earlier control trials. Jacobs \& Terhune (2002) tested an Airmar dB Plus ADD (consisting of an array of 4 transducers, p-p source level 172 re $1 \mu \mathrm{Pa}$ ) after chasing harbour seals from a haul-out into the water. They found no differences between control and sound exposure sessions in surface positions taken by the animals. In another experiment, the authors could not find any effect of an acoustic barrier consisting of Airmar ADDs on harbour seals approaching a haul-out site. Similarly, ADDs used to protect salmon runs (Na- tional Marine Fisheries Service 1995) and fish farms (Norberg 1998) had little effect on otariids, although in some cases recruitment of new individuals was successfully prevented (National Marine Fisheries Service 1995). Installation of an Airmar dB Plus II deterrent device did not seem to result in a dramatic drop of predation levels inflicted by southern sea lions Otaria flavescens on a salmon farm in Chile (Vilata et al. 2010). However, a comparison of predation levels at the test site with the test site during the previous year and a control site on the same production cycle showed that the device caused a significant reduction in losses (Vilata et al. 2010). As the authors state, deployment was limited to a 3 mo period and long-term habituation was not evaluated. In an internal company report, Ace-Hopkins (2002a) presented a number of trials with his Ace-Aquatec device at different salmon farms in Scotland where potential predators are grey and harbour seals. He reported a reduction of fish damage at 2 farms while no effect was found at a third farm. Unlike other ADDs that produce sounds at random or regular intervals, the Ace-Aquatec device uses a triggering system that senses salmon movements in response to predator presence (AceHopkins 2002b). Fjälling et al. (2006) used a Lofitech seal scarer that emitted at a source level of $179 \mathrm{~dB}$ re $1 \mu \mathrm{Pa}$ to protect salmon traps from grey seal predation in the Baltic Sea (an unmodified version of the device operates at a duty cycle of about 9 to $10 \%$; the authors partly used a modified version with a duty cycle of $4.5 \%$ by reducing the pulse length to $250 \mathrm{~ms}$ ). The use of this seal scarer resulted in both higher catch rates and lower fish damage during the test periods over 3 consecutive years. However, the effect waned towards the end of the season in each year. Similarly, Graham et al. (2009) found that a Lofitech ADD that was deployed in 2 rivers in Scotland for a 5 mo period reduced the number of seals upstream of the device by $50 \%$. However, overall numbers of seals in the river system were unaffected.

These experiments showed substantial variation in behavioural responses across studies and study sites. This is probably the result of a variety of poorly understood factors influencing animal responses to sound in the wild. In a recent study, Götz \& Janik (2010) demonstrated that the behavioural avoidance responses to sound in phocid seals were influenced by food motivation, learning processes, sound type and sensation levels (the level by which a sound exceeds the hearing threshold). The study also tested sounds of 4 commercially available ADDs (Terescos, Ace-Aquatec, Lofitech and Airmar dB plus). Study subjects habituated rapidly to all sound types when 
played at a received level of $146 \mathrm{~dB} 1 \mu \mathrm{Pa}(\mathrm{rms})$ and food was presented next to the sound projector. Most ADD manufacturers claim a deterrence effect at this received level (e.g. Lofitech). Thus, these results generally question whether current ADDs can be efficient. However, the same study also demonstrated that without food presentation, ADD sounds of 3 out of 4 manufacturers yielded a deterrence effect down to received levels of $135 \mathrm{~dB}$ re $1 \mu \mathrm{Pa}$.

Indirect information on the effectiveness of current ADDs has been obtained by analysing the results of a questionnaire survey in Scotland where a variety of devices were in use (Quick et al. 2004). Only 23\% of the fish farmers reported ADDs to be very effective, $50 \%$ reported moderate, $15 \%$ poor and $7 \%$ little efficiency. As in other areas (e.g. Mate et al. 1987) some of the farmers believed them to even attract seals. Perceived performance of currently available commercial deterrent systems (evaluated through interviews) was even worse in Chile where predation is inflicted by southern sea lions (Sepulveda \& Oliva 2005). Acoustic deterrent systems were considered ineffective at 12 out of 16 sites, while only 4 sites claimed high or moderate efficiency.

The reasons for differences in reported efficiency may be diverse, and include the exact ADD deployment method and schedule, the animals' foraging motivation, differences between populations and species in reactions to human actions and differences in sound propagation characteristics of the habitat. The potential reasons for the loss of effectiveness observed in most studies over time are also varied. These are the induction of hearing damage due to ADD sound exposure (Reeves et al. 1996), habituation to sounds (Groves \& Thompson, 1970), learning that sounds indicate the location of a fish farm (the 'dinner bell effect') and learning how to avoid the sound by swimming with the head above the surface.

\section{ECOLOGICAL IMPACTS ON TARGET AND NON-TARGET SPECIES}

Acoustic devices could cause negative impacts on animals in 4 different ways. They could cause damage to the ear due to high sound pressure, mask sounds used for communication, orientation or prey detection, lead to avoidance and an exclusion of animals from parts of their habitat, and/or induce detrimental physiological changes, such as increased stress hormone levels.

To affect the behaviour of an animal a sound must be audible. A high-power ADD (e.g. Ferranti-
Thompson 4 ) can be audible to the harbour porpoise Phocoena phocoena for up to $10 \mathrm{~km}$ under low ambient noise (Taylor et al. 1997). Similarly, a harbour seal could potentially hear a device with a source level of $175 \mathrm{~dB}$ re $1 \mu \mathrm{Pa}$ at distances of 1.4 to $2.9 \mathrm{~km}$ in quiet conditions (Terhune et al. 2002). The effects on fish and other marine life with less sensitive hearing may be more localized, but could still be detrimental. We will now review the potential effects of ADD sounds on marine life.

Impacts on target species should be considered a concern for ecologists, managers and the industry alike. If ADDs cause permanent hearing damage, this would create a problem not only from a conservation point of view, but also from a commercial perspective as efficiency of the devices would be reduced. It is also important to note that hearing damage first affects the outer hair cells in the cochlea, which leads to only a small rise of the hearing threshold. However, even at this level, hearing damage causes a diminution of the dynamic range and a loss of the frequency discrimination ability (see Moore (1997) for a review on psychophysical effects of hearing damage). As pinnipeds are likely to rely on passive acoustics for prey detection (Schusterman et al. 2000) and mating (van Parijs et al. 2000), sensory effects caused by even weak hearing loss would probably reduce the ability to classify sounds. This could make these animals more dependent on predictable food sources such as farmed fish and affect their reproductive success.

\section{Hearing damage}

\section{General considerations}

There is controversy over the effects of ADDs on cetacean and pinniped hearing. Although manufacturers reject the possibility of hearing damage caused by their ADDs (Ace-Hopkins 2002b), researchers say that this concern can neither be proven nor dismissed at present (Gordon \& Northridge 2002). If an animal is exposed to stimuli that are above a certain level, hearing damage can occur as a temporary but fully recoverable shift of the hearing threshold (temporary threshold shift, TTS). If an animal is exposed to sound pressure levels (SPLs) beyond the TTS level or for longer durations, recovery may not be possible and the threshold shift becomes permanent (permanent threshold shift, PTS). The risk of hearing damage is considered to be a function of SPL and exposure time (Eldred et al. 1955). For instance, a sound with a short 
duration can be safely presented at a higher source level than a longer one. It has been suggested that stimuli of equal acoustic energy carry the risk of causing similar damage ('equal energy hypothesis'; Eldred et al. 1955). Therefore, sound exposure level (SEL) was suggested as a measure for defining safe exposure levels: SEL $=\mathrm{SPL}+10 \log _{10}(t)$, where $t$ is the exposure time in seconds, and SPL is the root mean square sound pressure level (Southall et al. 2007, see Madsen 2005 for equation). However, the equal energy hypothesis has recently been challenged by studies showing that disproportionally higher SELs are required to cause a TTS when exposure times are short (Mooney et al. 2009a,b, Finneran et al. 2010a; see also Supplement 1 at www.int-res.com/articles/ suppl/m492p285_supp.pdf). The onset of a TTS in odontocetes occurs at a SEL between 193 and $214 \mathrm{~dB}$ re $1 \mathrm{\mu Pa}^{2} \mathrm{~s}$ (Finneran et al. 2000, 2002, 2005, 2010a,b, Schlundt et al. 2000, Nachtigall et al. 2004, Mooney et al. 2009a,b) while pinnipeds developed a TTS at levels of about $183 \mathrm{~dB}$ re $1 \mu \mathrm{Pa}^{2} \mathrm{~s}$ (Kastak et al. 2005). In a harbour porpoise exposed to short transient noise pulses, a TTS was found at a lower level of $164 \mathrm{~dB}$ re $1 \mu_{\mathrm{Pa}^{2}} \mathrm{~s}$ (Lucke et al. 2009).

Marine mammal noise exposure criteria that can be used to predict the potential for hearing damage caused by ADDs have been developed based on available information on TTSs and permanent hearing damage in a range of taxa (Southall et al. 2007). The Southall et al. (2007) review is impressive in scope and provides highly valuable information, but we believe that there is room for improvement when using the criteria proposed in it. The main problem is that frequency weighting functions (M-weighting) suggested by Southall et al. (2007) cannot be considered conservative. This has mostly to do with the fact that animals in TTS studies used to derive exposure criteria were not always tested within their most sensitive range of hearing or in some cases tested individuals that had elevated hearing thresholds (see Supplement 1). We therefore suggest an alternative, more conservative approach that references SELs to the test subject's hearing threshold (sound exposure sensation level, $\left.\mathrm{SEL}_{\text {sens }}\right)$. This has previously been suggested by Kastak et al. (2005) and should be considered as a complementary rather than alternative approach. It acknowledges the fact that in spite of recent advances there is still considerable uncertainty when predicting permanent hearing damage in marine mammals. Supplement 1 explains the derivation of the unit of $\mathrm{SEL}_{\text {sens. }}$. Supplement 2 at www.int-res.com/articles/suppl/m492p285_supp .pdf provides the calculations of the impact zones for each species group. We predicted zones within which temporary and permanent hearing damage might occur for several exposure scenarios, taking differences in the devices' SPL and pulse emission pattern into account (Tables 2 \& 3). This was achieved by choosing 2 cumulative SELs (203 dB re $1 \mu \mathrm{Pa}^{2} \mathrm{~s}$ and $221.6 \mathrm{~dB}$ re $1 \mu \mathrm{Pa}^{2} \mathrm{~s}$ ) and then calculating corresponding impact zones within which an animal would have to reside for a specified amount of time to suffer the respective effect. Therefore, each impact zone (Table 2) has a corresponding exposure time required to cause the effect (Table 3). Impact zones (Table 2) are provided using the impact criteria provided by Southall et al. (2007), data by Lucke et al. (2009), as well as our new criteria based on $\mathrm{SEL}_{\text {sens. }}$. In addition, long-term exposure scenarios that model accumulation of hearing damage over months or years were reviewed (see Supplement 2).

The exposure times needed to cause a TTS or PTS within the respective impact zones differ remarkably between different devices (Tables $2 \& 3$ ), which is the result of differences in pulse emission patterns, pulse length and source level. Comparably shorter expo-

Table 2. Zones of temporary and permanent threshold shift for a shortand longer-term exposure scenario based on cumulative sound exposure levels (SELs). A cumulative SEL of $203 \mathrm{~dB}$ re $1 \mathrm{\mu Pa}^{2} \mathrm{~s}$ is equivalent to continuous exposure for $10 \mathrm{~s}$ at $193 \mathrm{~dB}$ re $1 \mu \mathrm{Pa}$, while $221.6 \mathrm{~dB}$ re 1 $\mu \mathrm{Pa}^{2} \mathrm{~s}$ is equivalent to continuous exposure for $720 \mathrm{~s}(10 \mathrm{~min})$ at $193 \mathrm{~dB}$ re $1 \mu \mathrm{Pa}$. The impact zone refers to the range within which the cumulative SEL will exceed the respective criterion for temporary or permanent hearing damage. These zones have to be interpreted in conjunction with the exposure times given for the respective devices in Table 3

\begin{tabular}{|c|c|c|c|}
\hline Species & \multicolumn{3}{|c|}{$\begin{array}{l}\text { threshold shift } \\
\text { caused by a cumulative SEL of: }\end{array}$} \\
\hline Common seal & $10 \mathrm{~m}^{\mathrm{a}}$ & $7 \mathrm{~m}^{\mathrm{a}}$ & $60 \mathrm{~m}^{\mathrm{a}}$ \\
\hline Porpoise & $\begin{array}{c}89 \mathrm{~m}^{\mathrm{c}} \\
345 \mathrm{~m}^{\mathrm{b}}\end{array}$ & $\begin{array}{c}9 \mathrm{~m}^{\mathrm{c}} \\
35 \mathrm{~m}^{\mathrm{b}}\end{array}$ & $\begin{array}{c}76 \mathrm{~m}^{\mathrm{c}} \\
295 \mathrm{~m}^{\mathrm{b}}\end{array}$ \\
\hline $\begin{array}{l}\text { Delphinids } \\
\quad \text { Tursiops spp. }\end{array}$ & $\begin{array}{l}2.5 \mathrm{~m}^{\mathrm{a}} \\
175 \mathrm{~m}^{\mathrm{b}}\end{array}$ & $\begin{array}{c}2 \mathrm{~m}^{\mathrm{a}} \\
18 \mathrm{~m}^{\mathrm{b}}\end{array}$ & $\begin{array}{l}15 \mathrm{~m}^{\mathrm{a}} \\
150 \mathrm{~m}^{\mathrm{b}}\end{array}$ \\
\hline Orcinus sp. & $748 \mathrm{~m}^{\mathrm{b}}$ & $79 \mathrm{~m}^{\mathrm{b}}$ & $642 \mathrm{~m}^{\mathrm{b}}$ \\
\hline $\begin{array}{l}{ }^{a} \text { Southall et al. } \\
\text { ments } 1 \& 2)_{i}{ }^{c}\end{array}$ & $\begin{array}{l}\text { 7); }{ }^{\text {b }} \mathrm{SEL}_{\text {sens }} \text { pre } \\
\text { e et al. (2009) }\end{array}$ & nted in & Daper (see Supple- \\
\hline
\end{tabular}


Table 3. Exposure times required to reach the cumulative sound exposure level needed to cause the impact zones given in Table 2. In some devices multiple scenarios are given to take typical deployment strategies and differing information on duty cycles into account. The duty cycle (dc) in the first column refers to the time during which an emission (e.g. pulse train) is produced. In devices which are typically used with multiple transducers the resulting emission duty cycle is stated. The calculation of the cumulative sound exposure was based on the effective duty cycle (rather on the emission duty cycle) to take pulse length and pulse interval pulse trains into account (see Supplements $1 \& 2$ )

\begin{tabular}{|c|c|c|}
\hline $\begin{array}{l}\text { Acoustic deterrent } \\
\text { device }\end{array}$ & \multicolumn{2}{|c|}{ Time needed to reach an SEL of: } \\
\hline \multicolumn{3}{|l|}{ Airmar (@192 dB re 1 pPa) } \\
\hline $50 \%$ dc & $11 \min 49 \mathrm{~s}$ & 14 h 29 min \\
\hline $200 \%$ dc (4 transducers) & $3 \min$ & $3 \mathrm{~h} 37 \mathrm{~min}$ \\
\hline \multicolumn{3}{|l|}{ Airmar (@ 198 dB re $1 \mu \mathrm{Pa}$ ) } \\
\hline $50 \% \mathrm{dc}$ & $3 \min 1 \mathrm{~s}$ & $3 \mathrm{~h} 38 \mathrm{~min}$ \\
\hline $200 \%$ dc (4 transducers) & $45 \mathrm{~s}$ & $55 \min$ \\
\hline \multicolumn{3}{|l|}{ Ace-Aquatec } \\
\hline $10 \% \mathrm{dc}^{\mathrm{a}}$ & $7 \min 52 \mathrm{~s}$ & $9 \mathrm{~h} 30 \mathrm{~min}$ \\
\hline $30 \%(3 \text { transducers })^{a}$ & $2 \min 37 \mathrm{~s}$ & $3 \mathrm{~h} 10 \mathrm{~min}$ \\
\hline \multicolumn{3}{|l|}{ Lofitech } \\
\hline $12 \% \mathrm{dc}$ & $17 \min 29 \mathrm{~s}$ & $21 \mathrm{~h} 7 \mathrm{~min}$ \\
\hline $25 \% \mathrm{dc}$ & $8 \mathrm{~min} 24 \mathrm{~s}$ & $10 \mathrm{~h} 8 \mathrm{~min}$ \\
\hline \multicolumn{3}{|l|}{ Terecos } \\
\hline $11 \% \mathrm{dc}$ & $47 \min 55 \mathrm{~s}$ & 57 h $51 \mathrm{~min}$ \\
\hline $33 \%$ (3 transducers) & $15 \min 58 \mathrm{~s}$ & $19 \mathrm{~h} 17 \mathrm{~min}$ \\
\hline
\end{tabular}

alternative approach using $\mathrm{SEL}_{\text {sens }}$ would however predict somewhat larger TTS zones for odontocetes ranging from $175 \mathrm{~m}$ (bottlenose dolphin) to $748 \mathrm{~m}$ (killer whale).

Following criteria suggested by Southall et al. (2007), a PTS in common seals Phoca vitulina would be caused by exposure of the same duration if the animal was within $7 \mathrm{~m}$ of the device. The noise criteria by Southall et al. (2007) suggest that delphinids will only be affected when remaining within a couple of metres from the device. According to data by Lucke et al. (2009), porpoises would suffer permanent damage when staying within a zone of $9 \mathrm{~m}$ around a transducer. Our more conservative approach based on $\mathrm{SEL}_{\text {sens }}$ yields larger PTS zones of up to $18 \mathrm{~m}$ (bottlenose dolphin), $35 \mathrm{~m}$ (harbour porpoise) and $79 \mathrm{~m}$ (killer whale) for odontocetes.

\section{PTS: longer-term exposure scenario (SEL $203 \mathrm{~dB}$ re $1 \mathrm{\mu Pa}^{2} \mathrm{~s}$ )}

The longer-term exposure scenario (Tables 2 \& 3) based on a cumulative SEL of $221.6 \mathrm{~dB}$ re $1 \mathrm{\mu Pa}^{2} \mathrm{~s}$ requires animals to be exposed to ADDs for between 55 min (Airmar array at high source levels) and $\sim 58 \mathrm{~h}$ (single Terecos). Southall et al. (2007) predict that such exposure will only cause PTS in odontocetes if animals remain within sure times are needed to cause an adverse effect on hearing in devices that operate at high source levels or at high duty cycles due to the deployment of multitransducer arrays (e.g. Airmar). For example, a 4 transducer Airmar array will reach the lower cumulative SEL used in our calculations (203 dB re $1 \mu \mathrm{Pa}^{2} \mathrm{~s}$ ) within 2 min $17 \mathrm{~s}$ or $45 \mathrm{~s}$ (depending on the source level), while a single Terecos device will have to run for almost $48 \mathrm{~min}$ to reach the same SEL.

TTS and PTS: short-term exposure scenario (SEL $203 \mathrm{~dB}$ re $1 \mu \mathrm{Pa}^{2} \mathrm{~s}$ )

Using the duty cycles given in Table 1, an exposure for $45 \mathrm{~s}$ to $48 \mathrm{~min}$ (depending on the model) is predicted to cause a TTS in harbour seals when animals are less than $10 \mathrm{~m}$ from the sound source. In the same short-term exposure scenario, delphinids would be affected at up to $3 \mathrm{~m}$ distance and harbour porpoise Phocoena phocoena potentially at up to $89 \mathrm{~m}$. Our
$15 \mathrm{~m}$ of one of the transducers. Data collected by Lucke et al. (2009) suggests that porpoises would suffer permanent damage within a zone of $76 \mathrm{~m}$. Our approach based on $\mathrm{SEL}_{\text {sens }}$ yields much larger impact zones of $295 \mathrm{~m}$ for porpoises, $150 \mathrm{~m}$ for bottlenose dolphin and $642 \mathrm{~m}$ for killer whales. Pinnipeds would suffer PTS at distances of up to $60 \mathrm{~m}$ from a transducer.

PTS: exposure over months or years

Predictions of exposure to low received levels over several months or years are associated with significant uncertainties and based on potentially problematic extrapolations (see Supplement 2). We would expect permanent hearing damage for pinnipeds within a zone of about $60 \mathrm{~m}$ from a device while odontocetes may be affected up to $40 \mathrm{~m}$ or more than $1 \mathrm{~km}$ from the farm depending on the assumptions made (see also Supplement 2). 
Fish and invertebrates

Impact zones for fish and other marine wildlife are much smaller or non-existent (see Supplement 2). Few data are available for these other taxa, but these suggest that fish and invertebrates are unlikely to be affected by current ADDs. The exception may be fish species with good hearing, however, even these may only be affected within a few metres of the device (see Supplement 2).

\section{Conclusions}

Effects of current ADDs on fish and invertebrates without specialized hearing are unlikely. However, current acoustic deterrence methods, particularly multi-transducer arrays operating at high source levels, may carry some risk of damaging hearing of pinnipeds and delphinids if animals stay in the vicinity of a fish farm for an extended time. Depending on the assumptions made, the acoustic characteristics of the device and the species hearing sensitivity, distances within which ADDs can cause permanent or temporary hearing damage range from negligible (several metres) to relevant (several hundred metres). However, we believe that as all calculations are based on relatively little data (mostly only one or a few animals were measured) the most precautionary approach should be considered. The extent of the risk will primarily depend on whether marine mammals are likely to stay in the vicinity of a fish farm (less than a few hundred metres) for long enough (e.g. over $1 \mathrm{~h}$ ) to be exposed to sufficient noise doses. This scenario may not be too unlikely, as aquaculture sites often attract shoals of wild fish, which in turn attract marine mammals. Marine mammals have been shown to ignore sound exposure when attracted to a simulated, potentially profitable foraging spot (Götz \& Janik 2010). Therefore, this risk should be taken into account, particularly in areas with a high density of fish farms using ADDs. If hearing damage is inflicted then this would most likely reduce fitness of the individuals involved and, if large parts of the population were affected, hearing loss could lead to effects on a population level.

\section{Masking}

In masking, the detection of one sound (signal) is influenced by a second sound (masker). There are many levels to masking, including energetic mask- ing, informational masking and effects of noise on attention and stress that affect information transmission (Clark et al. 2009). ADDs may have such an effect on marine mammal communication networks (Janik 2005) by decreasing detection distances of communication signals. Fletcher (1940) found that masking effects in mammals depend on the bandwidth of the masker (centred at the frequency of the signal) until it reaches a so-called critical bandwidth. Therefore, noise only masks a signal efficiently if it covers the frequency range of the signal of interest (but see Martin \& Pickett (1970) for a discussion of upward masking). Marine mammal communication and echolocation signals overlap strongly with those produced by current ADDs. Hence, there is significant potential for masking, particularly for devices that emit broadband noise (e.g. Ace-Aquatec, Terecos). The zone of masking can potentially extend up to the zone of audibility. However, cetacean and pinniped sensory physiology also provides ways to alleviate masking effects. Critical bandwidths in marine mammals are generally below $10 \%$ of the signal's centre frequency (Richardson et al. 1995). Additionally, masking effects are attenuated if the masker and signal come from different directions. Terhune (1974) found that the harbour seal's minimal audible angle distinction for clicks is $4.5^{\circ}$. Bottlenose dolphins Tursiops truncatus can distinguish sound sources that are presented at angles of less than $3^{\circ}$ apart (Renaud \& Popper 1975). Furthermore, bottlenose dolphin hearing sensitivity is direction-dependent (Au \& Moore 1984), which increases the capability of detecting signals in noise if noise source and target sound are spatially separated. Another way in which animals adapt to increased noise is by changing calling patterns. Beluga whales, for example, change their calling behaviour significantly by either producing less calls when close to a noise source or by increasing redundancy in calling when noise increases moderately (Lesage et al. 1999). Some of these changes are adaptations to natural noise, such as a decrease in calling rates when noise is high due to calling conspecifics (Quick \& Janik 2008).

The masking potential of ADDs has not been investigated directly, but the effects of vessel noise on communication space have been modelled for baleen whales (Clark et al. 2009) and delphinids (Erbe 2002, Jensen et al. 2009). These suggest that broadband noise can result in a significant reduction of active communication space. The fact that some ADDs produce broadband noise within a similar frequency range as small vessels but at much higher source levels certainly highlights the masking potential, partic- 
ularly in areas with dense fish farming. Further studies, incorporating direct sound field measurements from such areas, are needed to further assess this problem.

Most communication signals in fish are fundamentally lower than the frequency band in which most ADDs operate (see Zelick et al. 1999). However, hearing abilities (e.g. localization and frequency discrimination) in the majority of fish species are less sophisticated than in mammals (Fay \& Popper 1999), which might make them more prone to masking effects. Elevated detection thresholds as a result of masking have been shown in hearing generalists as well as specialists (Wysocki \& Ladich 2005, Vasconcelos et al. 2007). Fish species also seem to differ in their susceptibility to masking (Ramcharitar \& Popper 2004). A neuro-physiological study on goldfish (a hearing specialist) showed that responses of nerve fibres to tones between 400 and $800 \mathrm{~Hz}$ can be suppressed by maskers of a broad range of frequencies essentially covering most of the hearing range (Fay 1991). These studies show that masking of communication signals in fish is a possibility and could also be caused by noise that does not overlap with the communication signals. However, only few ADDs produce signals that are audible to fish with the exception of species that are hearing specialists. Therefore, the overall potential of current ADDs to mask fish sounds is probably rather low. Most invertebrates and sea turtles are unable to detect sounds in the frequency range of ADDs and are therefore unlikely to be affected (see Supplement 2).

\section{Habitat exclusion}

Behavioural reactions of marine mammals to noise have been documented for a variety of noise sources (Richardson et al. 1995). Avoidance responses to ADDs leading to an exclusion from the habitat have been well studied in harbour porpoises and killer whales. Olesiuk et al. (2002) carried out a study in the Broughton Archipelago (British Columbia) investigating effects of the Airmar ADD on harbour porpoise distribution in the respective observation area. When the ADD was switched on the number of animals detected dropped significantly to $1.9 \%$ and $3.8 \%$ of values in control sessions, depending on the sector scanned. Porpoises were completely excluded from an area of $400 \mathrm{~m}$ radius around the ADD and the number of sightings was still below $10 \%$ of the expected value at ranges between 2500 and $3500 \mathrm{~m}$ from the device. Johnston (2002) carried out an addi- tional experiment using a theodolite tracking method and found that porpoises did not approach an emitting ADD closer than $645 \mathrm{~m}$ (received level at this distance would be $128 \mathrm{~dB}$ re $1 \mu \mathrm{Pa}$ ). The average closest approaches were $991 \mathrm{~m}$ (in contrast to $363 \mathrm{~m}$ during control) and significantly fewer porpoises could be seen within a range of $1500 \mathrm{~m}$. In addition, porpoises moved out of the area after the ADD was switched on. In a more recent study, a Lofitech seal scarer was found to cause a reduction in harbour porpoise density down to $1 \%$ within an area of $1 \mathrm{~km}$ around the device (Brandt et al. 2013). Here, porpoises showed avoidance responses within $1.9 \mathrm{~km}$ of the device where received levels exceeded $122 \mathrm{~dB}$ re $1 \mu \mathrm{Pa}$. Morton \& Symonds (2002) reported a considerable decrease in killer whale sightings in Johnstone Strait, Canada after ADDs (most likely different brands) had been introduced on fish farms and a recovery of sighting rates after fish farmers stopped using them. This change did not correlate with changes in local food availability. Interestingly, no differences in sightings of seals were observed. This study covers a period of $15 \mathrm{yr}$ and therefore indicates that killer whales, in contrast to seals, did not habituate to ADDs. Morton (2000) found that Pacific white-sided dolphins Lagenorhynchus obliquidens abundance decreased after ADDs were introduced in the area.

Less information is available on behavioural disturbance of fish by noise similar to that used in ADDs, but these effects might be limited to species with sophisticated hearing. Kraus et al. (1997) found that catch rates in gillnets with pingers were lower, but a causal relationship to the sound could not be proven. Experiments with salmon smolts showed that a $10 \mathrm{~Hz}$ signal caused avoidance responses at particle accelerations of $0.01 \mathrm{~m} \mathrm{~s}^{-2}$ (3 $\mathrm{m}$ distance). In contrast, a $150 \mathrm{~Hz}$ signal did not cause avoidance reactions even when animals were right next to the sound source where particle acceleration was $4 \mathrm{~m} \mathrm{~s}^{-2}$, which is about $114 \mathrm{~dB}$ above the hearing threshold (Knudsen et al. 1994). Wardle et al. (2001) used video observations and tagging methods to monitor behaviour of cold water reef fish (including pollack Pollachius pollachius) during airgun emissions; however, in contrast to the sounds produced by ADDs, airgun pulses fall in the most sensitive frequency range of fish. All fish showed C-starts (a reflex initiated by quick motor neurons) in response to every sound emission at p-p SPLs higher than $195 \mathrm{~dB}$ re $1 \mu \mathrm{Pa}$, but directional avoidance responses only occurred when fish could also see the explosion. No behavioural or physiological responses were found in cod Gadus morhua exposed to ultrasonic clicks at $50 \mathrm{kHz}$ (Schack et al. 
2008). Kastelein et al. (2007) tested behavioural responses of a variety of North Sea fish species to several commercially available pingers used to reduce bycatch of cetaceans in gillnets. The authors concluded that, in particular, pingers with signals higher than $10 \mathrm{kHz}$ are less likely to affect fish species. In a second experiment, Kastelein et al. (2008) showed that none of the tested North Sea fish species exhibited a C-start startle reflex to pure tones at frequencies higher than $5 \mathrm{kHz}$, even at the highest source level tested (170 to $180 \mathrm{~dB}$ re $1 \mu \mathrm{Pa}$ depending on frequency). The highest frequencies that elicited a Cstart response in any of the fish was $4 \mathrm{kHz}$ in Atlantic herring Clupea harengus, with an average 50\% response threshold of $170 \mathrm{~dB}$ re $1 \mu \mathrm{Pa}$. Although all this points towards habitat exclusion in fish being less likely, some fish developed ultrasound detection capabilities, presumably to avoid echolocating predators (Mann et al. 1997, Wilson et al. 2011). In shad Alosa alosa, ultrasonic single pulses presented at levels of $192 \mathrm{~dB}$ re $1 \mu \mathrm{Pa}(\mathrm{p}-\mathrm{p})$ did not cause a C-start or directional avoidance response, but trains of such pulses at repetition rates from 20 to 250 clicks s$^{-1}$ did (Wilson et al. 2011). Similarly, alewives Alosa pseudoharengus respond to broadband pulses at frequencies between 117 and $130 \mathrm{kHz}$, with an avoidance response if predation is likely. Some ADDs produce such pulse trains so that habitat exclusion is a possibility in the vicinity of farms. While overall habitat exclusion may appear less likely for fish, empirical data is lacking for many species and behavioural reactions to noise in fish are still poorly understood.

\section{PROBLEMS AND POTENTIAL SOLUTIONS}

\section{The problem of impact on cetaceans: frequency bands}

A major difference in the hearing systems of pinnipeds and odontocetes is that the latter are much more sensitive to frequencies above $5 \mathrm{kHz}$ (Fig. 1). In humans, contours of perceived equal loudness roughly follow the hearing threshold in the most sensitive frequency range, but contours flatten towards the edge of the hearing range (Fletcher \& Munson 1933). Thus, sounds that have the same sensation level (i.e. they exceed the auditory threshold by a similar amount) are perceived as roughly equal in loudness even though this relationship breaks down at the edge of the auditory range. The importance of sensation levels is supported by a behavioural study on terrestrial mammals that demonstrated that aver- sion thresholds run roughly parallel to the hearing threshold (Campbell 1957). Most importantly, there is now direct empirical evidence for equal loudness contours roughly following the auditory threshold in a bottlenose dolphin that was trained to perform a 2-alternative forced choice task in which it had to report a tone as louder or weaker than a comparison tone (Finneran \& Schlundt 2011). Fig. 1 shows the hearing thresholds for a representative spectrum of marine wildlife. Odontocete hearing is generally 15 to $30 \mathrm{~dB}$ more sensitive than pinniped hearing in the frequency band from 4 to $40 \mathrm{kHz}$. This means that perceived loudness of sounds within the frequency band where ADDs operate is likely to be much higher for odontocetes than for pinnipeds. For example, at 10 $\mathrm{kHz}$ (the frequency used by the Airmar dB Plus II device) the hearing thresholds of most odontocetes are 15 to $20 \mathrm{~dB}$ lower than those of pinnipeds. This may in part explain why ADDs seem to have more pronounced effects on the behaviour of toothed whales than on that of pinnipeds. Therefore, although current ADDs operate at frequencies close to the most sensitive hearing of pinnipeds (20 to $30 \mathrm{kHz}$ ) these frequencies cannot be generally recommended, as hearing in odontocetes is even more sensitive in this band. Many cetaceans have their most sensitive hearing in the ultrasonic range between 30 and $50 \mathrm{kHz}$ (Fig. 1). If impact on odontocetes is to be mitigated an ADD should not produce energy above $5 \mathrm{kHz}$.

It appears that a frequency band between 1 and $2 \mathrm{kHz}$ for ADDs would be ideal for mitigating impact on odontocetes when targeting pinnipeds. Compared with the frequency band used at present in seal scarers, this would lower sensation levels in odontocetes by about $40 \mathrm{~dB}$ (Fig. 1), which could lead to a significant reduction in deterrence ranges for odontocetes. One concern might be that low-frequency sound can propagate over longer ranges, which could cause more noise pollution. Absorption coefficients are in the order of $0.06 \mathrm{~dB} \mathrm{~km}^{-1}$ at $1 \mathrm{kHz}$, compared with $0.7 \mathrm{~dB} \mathrm{~km}^{-1}$ at $10 \mathrm{kHz}$, the peak frequency of the Airmar device (Fisher \& Simmons 1977). The difference in transmission loss between a $1 \mathrm{kHz}$ and $10 \mathrm{kHz}$ signal at $5 \mathrm{~km}$ distance would therefore only be $\sim 3 \mathrm{~dB}$. A more serious concern than sound propagation is that lower-frequency signals would be more audible to fish and baleen whales and may therefore affect these species. Tests on baleen whales and hearing specialist fish would be required before low frequency ADDs were to be deployed in baleen whale habitat. However, we think that an impact on fish would be less likely. The audiograms of fish species with no specific adaptations generally show a rapid 

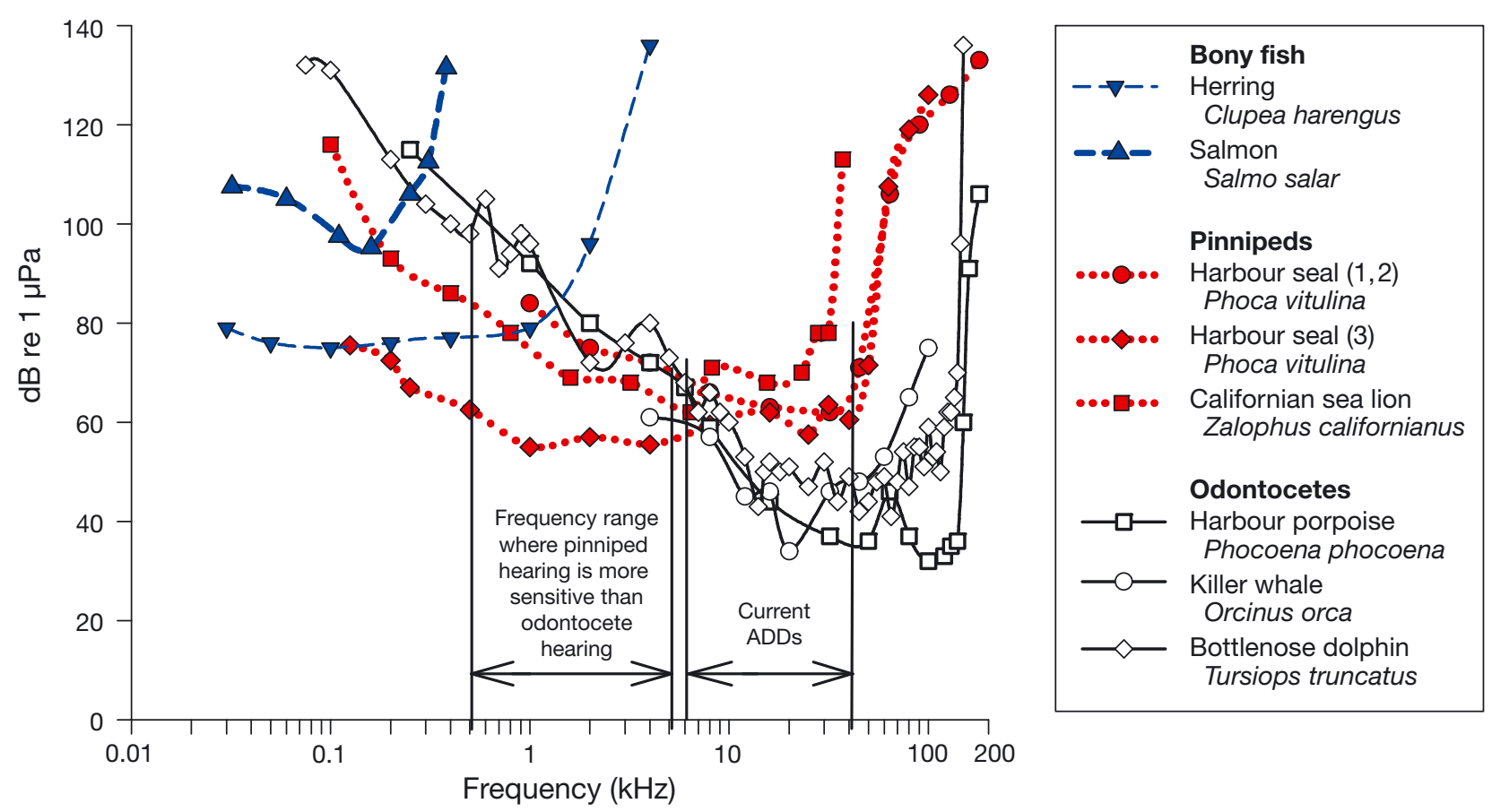

Fig. 1. Hearing thresholds for selected fish (blue dashed lines), pinnipeds (red dotted lines) and cetacean species (black solid lines). Note that most current acoustic deterrent devices (ADDs) operate in a frequency range where cetacean hearing is more sensitive than pinniped hearing. Harbour seal (1): Kastak \& Schusterman (1998; lower frequencies); harbour seal (2): Terhune (1988; higher frequencies); harbour seal (3): Kastelein et al. (2009); Californian sea lion: Reichmuth \& Southall (2012, subject 'Rio'); harbour porpoise: Kastelein et al. (2002); killer whale: Szymanski et al. (1999); bottlenose dolphin: Johnson (1967); herring: Enger (1967); salmon: Hawkins \& Johnstone (1978)

decline in sensitivity at frequencies above 500 to $1000 \mathrm{~Hz}$, making them less vulnerable to the suggested frequency range. Kastelein et al. (2007) showed that 6 out of 8 North Sea fish species did not exhibit startle responses (C-starts) at frequencies above $800 \mathrm{~Hz}$, even at the maximum tested SPL of $180 \mathrm{~dB}$ re $1 \mu \mathrm{Pa}$. However, there are some fish species with a broad hearing range. For example, American shad Alosa sappidissima are sensitive up to $180 \mathrm{kHz}$ (Mann et al. 1997). However, their absolute hearing sensitivity at frequencies between 1 and $2 \mathrm{kHz}$ is rather low $(\sim 130 \mathrm{~dB}$ re $1 \mu \mathrm{Pa})$, which makes them 40 to $50 \mathrm{~dB}$ less sensitive than most odontocetes at these frequencies. This still leaves hearing specialists with lower auditory thresholds (e.g. clupeids) as a concern. Although most hearing specialists among fish are pelagic animals and therefore less likely to occur around coastal fish farms, some use coastal spawning grounds. However, even hearing specialists such as herring are not more sensitive than odontocetes in the range of 1 to $2 \mathrm{kHz}$ (see Fig. 1). In conclusion, behavioural studies suggest that signals between 1 and $2 \mathrm{kHz}$ would not result in dramatic effects in most fish species, but may have some influence on hearing specialists close to the device.

\section{The problem of loudness perception: source levels}

The general paradigm applied in current ADDs is that a high source level sound is expected to cause physical discomfort or even pain and therefore results in the animal leaving an area. There are several problems involved when operating at the upper end of the dynamic range of an animal. In humans, the relationship between the magnitude of sensation $(\Psi)$ and the magnitude of the physical parameter $(\varphi)$ of a stimulus can be approximately modelled by Stevens' law (Stevens 1956):

$$
\Psi=k\left(\varphi-\varphi_{0}\right)^{m}
$$

with $k$ being a constant, $\varphi_{0}$ being the lowest perceivable physical stimulus (threshold) and $m$ being a modality-specific coefficient determining the essential shape of the function. In the human auditory system $m=0.6$; however, other sensory modalities have been found to have exponents higher than 1.0, e.g. $m=3.6$ for pain caused by electric shocks (Fig. 2; Stevens 1961). Therefore, in the auditory system, a given increase of the level of a high sound pressure stimulus leads only to a small increase of the per- 


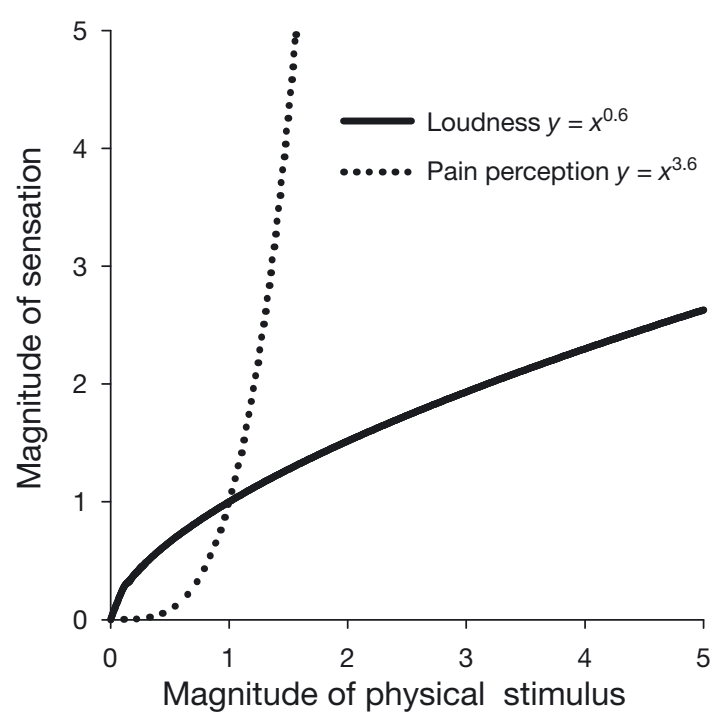

Fig. 2. Qualitative representation of Stevens' law (arbitrary units)

ceived loudness, while the same increase of a low sound pressure stimulus would lead to a stronger increase in perceived loudness (Fig. 2). In this context 'increase' does not refer to a ratio but means adding a defined sound pressure value. Thus, an increase of sound pressure in the upper range of the curve in Fig. 2 can be expected to disproportionately increase the risk of damaging the ear without yielding a much stronger aversive effect. In humans, the perceived loudness of a sound is generally measured using the sone scale. On the sone scale a doubling directly reflects a doubling of perceived loudness. One sone means that a sound has a perceived loudness equal to that of a $40 \mathrm{~dB}$ re $20 \mu \mathrm{Pa}$ tone at $1 \mathrm{kHz}$ in air for humans. The perceived loudness in sone $(L)$ can be calculated by the equation $L=0.01\left(p-p_{\mathrm{o}}\right)^{-0.6}$ where $p$ is the sound pressure in $\mu \mathrm{Pa}$ and $p_{\mathrm{o}}$ is the effective hearing threshold (Scharf 1978). Fig. 3 applies Stevens' law to the harbour seal hearing threshold and shows different sound sources on a SPL versus perception scale. This is purely done for illustrative purposes and should not be interpreted as a claim that these human psychophysical parameters are directly applicable to marine mammals. On this scale, background noise in sea state 2 would lie between 2 and 3 sone. The lowest level of observed avoidance for harbour seals described by Kastelein et al. (2006b) would lie at about 6 sone (Fig. 3). Fig. 3 also shows that most seal scarers operate at the upper edge of the dynamic range of the animals (800 sone).

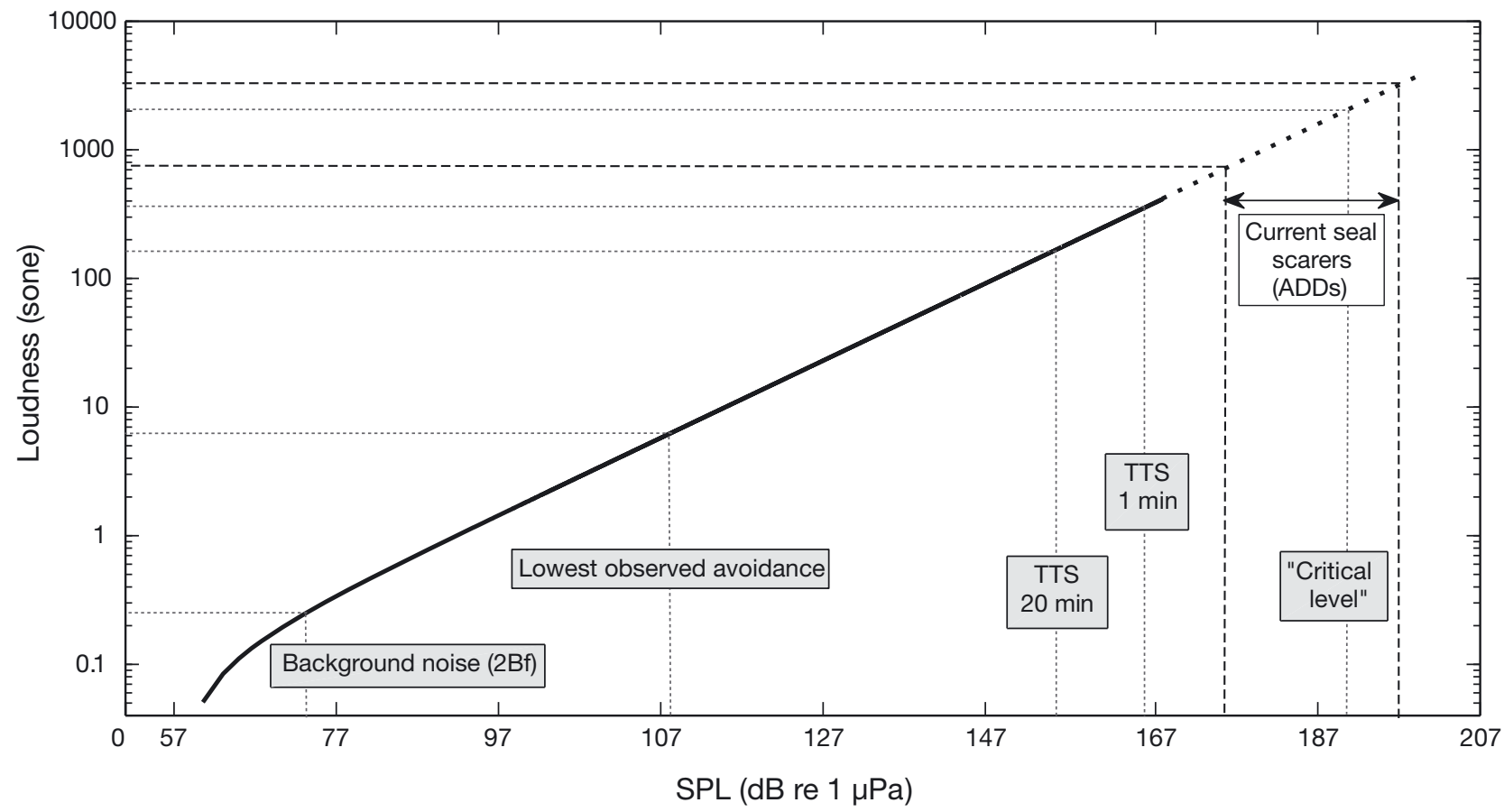

Fig. 3. Theoretical loudness scale for the harbour seal. The $y$ axis shows the perceived loudness in sones; a doubling of the loudness in sones reflects a doubling in perceived loudness. The $x$ axis represents the sound pressure level (SPL) with $57 \mathrm{~dB}$ re $1 \mu \mathrm{Pa}$ as the hearing threshold at $2.5 \mathrm{kHz}$ (Kastak et al. 2005). TTS means that the source level causes a temporary threshold shift if the animal is exposed for the mentioned amount of time (based on sound exposure levels measured by Kastak et al. 2005). Values for current seal scarers are source levels at $1 \mathrm{~m}$ distance. The lowest observed avoidance threshold is taken from Kastelein et al. (2006b) and critical levels are based on the data reviewed in our discussion on hearing damage, 2Bf: Beaufort sea state 2 
Some ADDs produce pulse trains with very short pulse durations of less than $2 \mathrm{~ms}$, while others produce pulse trains with pulses of several hundred ms or continuous noise. While the perceived loudness and possibly also the risk of hearing damage is lower in a device emitting short pulses, short inter-pulse intervals can counter this effect.

In humans, pain thresholds are 130 to $140 \mathrm{~dB}$ above the auditory threshold (Spreng 1975), which is close to SPLs at which an impulsive noise causes hearing damage (135 dB above auditory threshold; Danielson et al. 1991). Thus, current seal scarers are either not likely to cause 'pain' or if they do they are also likely to cause hearing damage. Apart from immediate damage, long-term exposure to moderate levels can also lead to permanent damage. This can easily occur without pain. For example, students working in entertainment venues have been shown to have PTSs up to a maximum of $30 \mathrm{~dB}$ (Sadhra et al. 2002). Therefore, no attempt should be made to increase the source level used at present or, indeed, use devices that emit sound continuously at source levels that fall at the upper end of the dynamic range close to the suspected pain threshold. Several studies on terrestrial mammals showed that the risk of damage from exposures to brief impulses is substantially increased if a stimulus exceeds the auditory threshold by 130 to $135 \mathrm{~dB}$ (Danielson et al. 1991, Levine et al. 1998). This so called 'critical level' should ideally never be exceeded (Fig. 3).

Our examples here were based on human sound perception, as little data is available for marine mammals. While such direct comparisons need to be looked at critically, they can be useful to visualise basic principles in mammalian hearing and therefore develop a more accurate framework that can be used to address the problems related to ADDs. We clearly need to expand our studies on marine mammal hearing to include effects such as loudness perception. We suggest that the actual source level of an ADD should be based on models that take likely exposure time and received level combinations into account to ensure both efficiency and minimal impact on the auditory system of target and non-target species.

\section{The aversiveness of sound stimuli}

In the light of the previous consideration, it would be beneficial to exploit factors other than loudness for deterring pinnipeds. Zwicker \& Fastl (1990) developed a model to describe what makes sound pleasant or unpleasant for humans. The relevant psy- chophysical parameters in the model are sharpness, roughness, tonality and loudness. In humans, roughness of a stimulus can be maximised by applying a 70 $\mathrm{Hz}$ frequency modulation to a carrier signal. The perceived pleasantness of a sound is likely to be based on the general functioning of the mammalian auditory system (Plomp \& Levelt 1965), but it may be worthwhile testing whether animals judge sounds in the same way as humans. Götz \& Janik (2010) tested sounds based on the psychophysical model of unpleasantness by Zwicker \& Fastl (1990) with freeranging seals around a haul-out site and found that the supposedly more aversive sound types elicited stronger and longer-lasting avoidance responses compared with control sounds and ADD sounds. However, this effect was not found with captive animals in a situation where animals were highly motivated to approach a food source.

\section{How to prevent habituation?}

Experimental playbacks with harbour seals in a pool resulted in an exclusion of the animals from a zone with received levels higher than 108 re $1 \mu \mathrm{Pa}$ without habituation in 7 consecutive playback sessions per sound type used (Kastelein et al. 2006b). The fact that seals predating on fish farms appear to tolerate much higher exposure levels shows that food motivation must have a major influence on deterrence. Indeed, harbour and grey seals have been shown to habituate rapidly to sounds in a context that simulates strong food motivation (Götz \& Janik 2010). In addition, the observation that odontocetes do not seem to habituate to ADDs in areas where they do not forage on farmed fish (Morton \& Symonds 2002) indicates that food motivation is important with respect to habituation.

Several manufacturers state that using highly variable sound types prevents habituation. However, empirical data for animals in a feeding context demonstrate that habituation occurs quickly even if stimulus types are varied (Götz \& Janik 2010). It is likely that trying to prevent habituation will not be possible unless a stimulus has strong aversive properties (see Skinner 1969 and Pryor 1987 for marine mammals). It may be possible to apply classical conditioning paradigms in the following way: an unconditioned stimulus, e.g. a fish treated with an emetic substance that causes sickness, is associated with a conditioned stimulus, e.g. an artificial acoustic signal with no biological meaning. After several pairings the conditioned stimulus is able to cause the condi- 
tioned responses, which consists of the same behavioural pattern as the unconditioned response. Unfortunately, reinforcement methods are limited in an underwater environment and the only known way is to use emetics (e.g. ivory soap, LiCl). Emetics have been shown to be temporarily successful against California sea lions (Kuljis 1984, Costa 1986), but some animals learnt to avoid treated fish and continued to feed on the natural salmon run (National Marine Fisheries Service 1996). Pairing of food aversion learning with non-gustatory modalities (e.g. sound) does not seem to work very effectively (Nachman \& Ashe 1977).

An alternative may be found by studying learning processes in relation to repeated stimulus elicitation. The dual process theory of habituation predicts that reactions to repeated presentations of a stimulus are always influenced by a decreasing (sensitisation) and increasing (habituation) component (Groves \& Thompson 1970). These processes have been studied extensively in simple reflexes, such as the acoustic startle response (Koch \& Schnitzler 1997). The startle response constitutes a pattern that involves flexor muscle contraction and is mediated by a simple oligo-synaptic reflex arc in the brainstem (Koch \& Schnitzler 1997). Pilz \& Schnitzler (1996) showed that latencies of the responses shorten with repeated exposures (sensitisation), while the magnitude of flexor muscle contraction slowly declines (habituation). For an application in an ADD, one can try to exploit the sensitising components of the physiological process. In this context, the startle reflex itself is an interesting candidate as it has been argued that its function is to facilitate flight responses (Pilz \& Schnitzler 1996). The startle reflex is only elicited by isolated sound pulses that have rise times shorter than 15 to $20 \mathrm{~ms}$ and minimum amplitudes of at least $80 \mathrm{~dB}$ above the auditory threshold (Koch \& Schnitzler 1997). Behavioural follow-up responses associated with the reflex have only recently been investigated in grey seals Halichoerus grypus. The majority of seals that were exposed to startling stimuli sensitised so that animals were increasingly likely to exhibit rapid flight responses, left the exposure pool and displayed clear signs of fear conditioning (Götz \& Janik 2011). Once sensitized, seals also avoided a known food dispenser and showed place avoidance even in control periods. In contrast, animals exposed to stimuli of similar SPL but with longer rise times habituated. These data indicate that the startle reflex plays an important role in mediating flight responses and that it can replace habituation with sensitisation.

\section{Acoustic deterrent devices used in other applications}

Pinniped ADDs have been suggested for use in applications such as exclusion of animals from areas of potential harm, i.e. marine construction sites employing pile-driving or tidal turbines. In these applications, the large deterrence ranges caused by ADDs in odontocetes are considered advantageous as they may ensure that animals will move out of the area within which they could suffer hearing damage (Brandt et al. 2013). Our suggestions for improving ADDs do generally also apply to these applications, but there are some differences. For example, exposure may be short-term and therefore habituation may be less of a problem (Brandt et al. 2013). However, pile-driving operation in areas of foraging habitat could be an exception as habituation occurs quickly when food motivation is high (Götz \& Janik, 2010). Given the potential effects of ADDs on marine mammal hearing, it may be a better solution to develop novel devices that are designed for purpose than to use currently available ADDs.

\section{CONCLUSIONS}

Efficiency of ADDs differed considerably between studies and study sites, which appears to be the result of differences in environmental conditions, populations, species, deployment or study design. Overall, efficiency seemed to range from poor to moderate with only a few examples where ADDs have been reported to be very effective, mainly when used in small and defined areas. Habituation to ADDs occurred within varying time frames, ranging from days to years, but it seemed to be a substantial problem in almost all studies. In contrast, odontocete species have been shown to be excluded from their habitat and long-term studies did not find any obvious habituation of these effects. This is most likely because odontocetes have more sensitive hearing in the devices' frequency range and apparently little motivation to feed on farmed fish in the studied areas. Therefore, to minimise effects of ADDs on odontocetes, one should shift to a lower frequency band than used at present, where the hearing sensitivity is higher in seals than in odontocetes. However, potential impacts on baleen whales and hearing specialist fish should be investigated if these occur in the vicinity of the fish farm. In no case should ADD signals contain much energy above $5 \mathrm{kHz}$ if odontocetes use habitats around the fish farm. In addition, meth- 
ods to reduce the duty cycle of ADDs should be found. Particularly, the effects of triggering methods or the presentation of isolated sound pulses exploiting autonomous reflexes related to flight behaviour, such as the startle reflex, should be more thoroughly tested. Signals should be short and duty cycles as low as possible to avoid hearing damage. The maximum SPL should be chosen based on available data for the onset of TTSs, assuming realistic exposure scenarios.

Most current, commercially available ADDs have some potential to damage the hearing of marine mammals, particularly if an animal stays in the vicinity of a fish farm for hours. In areas with a high density of fish farms, acoustic trauma may accumulate, similar to exposure of human workers to industrial noise. Therefore, only sound exposure protocols that use sound pressure level and exposure time combinations that are unlikely to cause hearing damage in pinnipeds and cetaceans should be used. Methods to prevent habituation, such as fear conditioning or the startle reflex, should be investigated in tests around fish farms. Furthermore, as food motivation appears to be a major factor, any newly established fish farm should try to prevent predation from the beginning. Most importantly, efficiency and target specificity of any device should be tested by independent studies before devices are deployed in fisheries or on fish farms.

Acknowledgements. This study was funded by the Scottish Government. We thank Peter T. Madsen, David A. Mann, Simon Northridge and Peter L. Tyack for comments on an earlier version of this manuscript.

\section{LITERATURE CITED}

Ace-Hopkins J (2002a) ANSS summary report. Ace-Aquatec company report AA-01- 043, www.aceaquatec.com/AA01-043.pdf, accessed 10 August 2011

Ace-Hopkins J (2002b) Humane predator control: the case for acoustics. Ace Aquatec company report AA-01-044, www.aceaquatec.com/AA-01-044.pdf, accessed $10 \mathrm{Au}-$ gust 2011

Akamatsu T, Nakamura K, Nitto H, Watanabe M (1996) Effects of underwater sound on escape behavior of Steller sea lions. Fish Sci 64:503-510

Anderson SS, Hawkins AD (1978) Scaring seals by sound. Mammal Rev 8:19-24

$>$ Au WWL, Moore PWB (1984) Receiving beam patterns and directivity indices of the Atlantic bottlenose dolphin. J Acoust Soc Am 75:255-262

> Brandt MJ, Hoschle C, Diederichs A, Betke K, Matuschek R, Nehls G (2013) Seal scarers as a tool to deter harbour porpoises from offshore construction sites. Mar Ecol Prog Ser 475:291-302

Campbell BA (1957) Auditory and aversion thresholds of rats for bands of noise. Science 125:596-597
Clark CW, Ellison WT, Southall BL, Hatch L, Van Parijs SM, Frankel A, Ponirakis D (2009) Acoustic masking in marine ecosystems: intuitions, analysis, and implication. Mar Ecol Prog Ser 395:201-222

Costa DP (1986) Physiological effects of prey aversion protocol using lithium chloride on Californian sea lions. Report to the US Marine Mammal Commission, Washington, DC

> Danielson R, Henderson D, Gratton MA, Bianchi L, Salvi R (1991) The importance of 'temporal pattern' in traumatic impulse noise exposures. J Acoust Soc Am 90:209-218

Eldred KM, Gannon WJ, von Gierke H (1955) Criteria for short time exposure of personnel to high intensity jet aircraft noise. WADC Technical Note 55-355, WrightPatterson Air Force Base, US Air Force, $\mathrm{OH}$

Enger P (1967) Hearing in herring. Comp Biochem Physiol A 22:527-538

Erbe C (2002) Underwater noise of whale-watching boats and potential effects on killer whales (Orcinus orca), based on an acoustic impact model. Mar Mamm Sci 18: 394-418

Fay RR (1991) Masking and suppression in auditory-nerve fibres of the goldfish, Carassius auratus. Hear Res 55: 177-187

Fay RR, Popper AN (1999) Comparative hearing: fish and amphibians. Springer, New York, NY

Finneran JJ, Schlundt CE (2011) Subjective loudness level measurements and equal loudness contours in a bottlenose dolphin (Tursiops truncatus). J Acoust Soc Am 130: 3124-3136

Finneran JJ, Schlundt CE, Carder DA, Clark JA, Young JA, Gaspin JB, Ridgway SH (2000) Auditory and behavioral responses of bottlenose dolphins (Tursiops truncatus) and a beluga whale (Delphinapterus leucas) to impulsive sounds resembling distant signatures of underwater explosions. J Acoust Soc Am 108:417-431

Finneran JJ, Schlundt CE, Dear R, Carder DA, Ridgway SH (2002) Temporary shift in masked hearing thresholds in odontocetes after exposure to single underwater impulses from a seismic watergun. J Acoust Soc Am 111: 2929-2940

> Finneran JJ, Carder DA, Schlundt CE, Ridgway SH (2005) Temporary threshold shift in bottlenose dolphins (Tursiops truncatus) exposed to mid-frequency tones. J Acoust Soc Am 118:2696-2705

> Finneran JJ, Carder DA, Schlundt CE, Dear RL (2010a) Growth and recovery of temporary threshold shift at $3 \mathrm{kHz}$ in bottlenose dolphins: experimental data and mathematical models. J Acoust Soc Am 127:3256-3266

> Finneran JJ, Carder DA, Schlundt CE, Dear RL (2010b) Temporary threshold shift in a bottlenose dolphin (Tursiops truncatus) exposed to intermittent tones. J Acoust Soc Am 127:3267-3272

Fisher FH, Simmons VP (1977) Sound absorption in seawater. J Acoust Soc Am 62:558-564

> Fjälling A, Wahlberg M, Westerberg H (2006) Acoustic harassment devices reduce seal interaction in the Baltic salmon-trap, net fishery. ICES J Mar Sci 63:1751-1758

Fletcher H (1940) Auditory patterns. Rev Mod Phys 12:47-65

Fletcher H, Munson WA (1933) Loudness, its definition, measurement and calculation. J Acoust Soc Am 5:82-108

Food and Agriculture Organization (2005) Global aquaculture production 1950-2003. Fisheries Global Information System, www.fao.org/fishery/figis, accessed 20 December 2005 
Fraker MA, Mate BR (1999) Seals, sea lions and salmon in the Pacific Northwest. In: Twiss JRJ, Reeves RR (eds) Conservation and management of marine mammals. Smithsonian Institution Press, Washington, DC, p 156-178

Geiger AC, Jeffries CJ (1987) Evaluation of seal harassment techniques to protect gill netted salmon. In: Mate BR, Harvey JT (eds) Acoustical deterrents in marine mammal conflicts with fisheries. ORESU-W-86-001, Oregon State University Sea Grant College Program, Newport, OR, p 37-55

Gordon J, Northridge S (2002) Potential impacts of acoustic deterrent devices on Scottish marine wildlife. Scottish Natural Heritage Commissioned Report F01AA404, http://ecologicuk.co.uk/SNHADDReview.pdf, accessed 12 September 2011

Götz T, Janik VM (2010) Aversiveness of sound in phocid seals: psycho-physiological factors, learning processes and motivation. J Exp Biol 213:1536-1548

Götz T, Janik VM (2011) Repeated elicitation of the acoustic startle reflex leads to sensitisation in subsequent avoidance behaviour and induces fear conditioning. BMC Neurosci 12:30

Graham IM, Harris RN, Denny B, Fowden D, Pullan D (2009) Testing the effectiveness of an acoustic deterrent device for excluding seals from Atlantic salmon rivers in Scotland. ICES J Mar Sci 66:860-864

> Groves PM, Thompson RF (1970) Habituation: a dualprocess theory. Psychol Rev 77:419-450

Harvey JT, Mate BR (1987) The feasibility of an acoustic harassment method to restrict movements of seals into Netart Bay, Oregon. In: Mate BR, Harvey JT (eds) Acoustical deterrents in marine mammal conflicts with fisheries. ORESU-W-86-001, Oregon State University Sea Grant College Program, Newport, OR, p 75-80

Hawkins AD (1985) Seal predation at salmon farms. Working Paper No. 8/85, Department of Agriculture and Fisheries for Scotland, Aberdeen

Hawkins AD, Johnstone ADF (1978) The hearing of salmon, Salmo salar. J Fish Biol 13:655-673

Jacobs SR, Terhune JM (2002) The effectiveness of acoustic harassment devices in the Bay of Fundy, Canada: seal reactions and a noise exposure model. Aquat Mamm 28: $147-158$

Janik VM (2005) Acoustic communication networks in marine mammals. In: McGregor PK (ed) Animal communication networks. Cambridge University Press, Cambridge, p 390-415

Jefferson TA, Curry BE (1996) Acoustic methods of reducing or eliminating marine mammal interactions with fisheries: Do they work? Ocean Coast Manage 31:41-70

> Jensen FH, Bejder L, Wahlberg M, Soto NA, Johnson M, Madsen PT (2009) Vessel noise effects on delphinid communication. Mar Ecol Prog Ser 395:161-175

Johnson CS (1967) Sound detection thresholds in marine mammals. In: Tavolga WN (ed) Marine bio-acoustics, Vol. 2. Pergamon Press, Oxford, p 247-255

$>$ Johnston DW (2002) The effect of acoustic harassment devices on harbour porpoises (Phocoena phocoena) in the Bay of Fundy, Canada. Biol Conserv 108:113-118

> Kastak D, Schusterman RJ (1998) Low-frequency amphibious hearing in pinnipeds: methods, measurements, noise, and ecology. J Acoust Soc Am 103:2216-2228

Kastak D, Southall BL, Schusterman RJ, Kastak C (2005) Underwater temporary threshold shift in pinnipeds: effects of noise level and duration. J Acoust Soc Am 118: 3154-3163

Kastelein RA, Bunskoek P, Hagedoorn M, Au WWL, de Haan D (2002) Audiogram of a harbor porpoise (Phocoena phocoena) measured with narrow-band frequency-modulated signals. J Acoust Soc Am 112:334-344

Kastelein RA, van der Heul S, Terhune JM, Verboom WC, Triesscheijn RJV (2006a) Deterring effects of $8-45 \mathrm{kHz}$ tone pulses on harbour seals (Phoca vitulina) in a large pool. Mar Environ Res 62:356-373

Kastelein RA, van der Heul S, Verboom WC, Triesscheijn RJV, Jennings NV (2006b) The influence of underwater data transmission sounds on the displacement behaviour of captive harbour seals (Phoca vitulina). Mar Environ Res 61:19-39

Kastelein RA, van der Heul S, van der Veen J, Verboom WC, Jennings N, de Haan D, Reijnders PJH (2007) Effects of acoustic alarms, designed to reduce small cetacean bycatch in gillnet fisheries, on the behaviour of North Sea fish species in a large tank. Mar Environ Res 64: 160-180

Kastelein RA, van der Heul S, Verboom WC, Jennings N, van der Veen J, de Haan D (2008) Startle response of captive North Sea fish species to underwater tones between 0.1 and $64 \mathrm{kHz}$. Mar Environ Res 65:369-377

Kastelein RA, Wensveen PJ, Hoek L, Verboom WC, Terhune JM (2009) Underwater detection of tonal signals between 0.125 and $100 \mathrm{kHz}$ by harbor seals (Phoca vitulina). J Acoust Soc Am 125:1222-1229

Knudsen FR, Enger PS, Sand O (1994) Avoidance response to low frequency sound in downstream migrating Atlantic salmon smolts, Salmo salar. J Fish Biol 45:227-233

> Koch M, Schnitzler HU (1997) The acoustic startle response in rats: circuits mediating evocation, inhibition and potentiation. Behav Brain Res 89:35-49

Kraus SD, Read AJ, Solow A, Baldwin K, Spradlin T, Anderson E, Williamson J (1997) Acoustic alarms reduce porpoise mortality. Nature 388:525

Kuljis BA (1984) Report on food aversion conditioning learning in sea lions (Zalophus californianus). NMFS Contract Rep No. 84-ABC-00167, National Marine Fisheries Service,

Lepper PA, Turner VLG, Goodson AD, Black KD (2004) Source levels and spectra emitted by three commercial aquaculture anti-predation devices. Proc 7th European Conf on Underwater Acoustics, ECUA, Delft

> Lesage V, Barette C, Kingsley MCS, Sjare B (1999) The effect of vessel noise on the vocal behavior of belugas in the St. Lawrence River estuary, Canada. Mar Mamm Sci 15:65-84

Levine S, Hofstetter P, Zheng XY, Henderson D (1998) Duration and peak level as co-factors in hearing loss from exposure to impact noise. Scand Audiol 27:27-36

Lucke K, Siebert U, Lepper PA, Blanchet MA (2009) Temporary shift in masked hearing thresholds in a harbor porpoise (Phocoena phocoena) after exposure to seismic airgun stimuli. J Acoust Soc Am 125:4060-4070

> Madsen RT (2005) Marine mammals and noise: problems with root mean square sound pressure levels for transients. J Acoust Soc Am 117:3952-3957

> Mann DA, Lu Z, Popper AN (1997) A clupeid fish can detect ultrasound. Nature 389:341

Martin ES, Pickett JM (1970) Sensorineural hearing loss and upward spread of masking. J Speech Hear Res 13: $426-437$ 
Mate BR, Harvey JT (1987) Acoustical deterrents in marine mammal conflicts with fisheries. ORESU-W-86-001, Oregon State University Sea Grant College Program, Newport, OR

Mate BR, Brown RF, Greenslaw CF, Harvey JT, Temte J (1987) An acoustic harassment technique to reduce seal predation salmon. In: Mate BR, Harvey JT (eds) Acoustical deterrents in marine mammal conflicts with fisheries. ORESU-W-86-001, Oregon State University Sea Grant College Program, Newport, OR, p 23-36

Mooney TA, Nachtigall PE, Breese M, Vlachos S, Au WWL (2009a) Predicting temporary threshold shifts in a bottlenose dolphin (Tursiops truncatus): the effects of noise level and duration. J Acoust Soc Am 125:1816-1826

> Mooney TA, Nachtigall PE, Vlachos S (2009b) Sonarinduced temporary hearing loss in dolphins. Biol Lett 5: 565-567

Moore BCJ (1997) An introduction to the psychology of hearing. Academic Press, San Diego

Morris DS (1996) Seal predation at salmon farms in Maine, an overview of the problem and potential solutions. Mar Technol Soc J 30:39-43

> Morton A (2000) Occurrence, photo-identification and prey of Pacific white-sided dolphins (Lagenorynchus obliquidens) in the Broughton Archipelago, Canada 19841998. Mar Mamm Sci 16:80-93

Morton AB, Symonds HK (2002) Displacement of Orcinus orca (L.) by high amplitude sound in British Columbia, Canada. ICES J Mar Sci 59:71-80

Nachman MJR, Ashe JH (1977) Stimulus characteristics in food aversion learning. In: Milgram NW, Krames L, Allowway TM (eds) Food aversion learning, Plenum Press, New York, NY, p 105-128

Nachtigall PE, Supin AY, Pawloski J, Au WWL (2004) Temporary threshold shifts after noise exposure in the bottlenose dolphin (Tursiops truncatus) measured using evoked auditory potentials. Mar Mamm Sci 20:673-687

Nash CE, Iwamoto RN, Mahnken CVW (2000) Aquaculture risk management and marine mammal interactions in the Pacific Northwest. Aquaculture 183:307-323

National Marine Fisheries Service (1995) Environmental assessment on protecting winter-run wild steelhead from predation by California sea lions in Lake Washington ship canal. NMFS Environmental Assessment Report, NMFS Northwest Regional Office, Seattle, WA, available at www.nmfs.noaa.gov

National Marine Fisheries Service (1996) Report of Gulf of Maine aquaculture-pinniped interaction task force. Office of Protected Resources, NMFS, Silver Spring, $\mathrm{MD}$

Norberg B (1998) Testing the effects of acoustic deterrent devices on California sea lion predation at a commercial salmon farm. NMFS-NWFSC-28, NMFS Northwest Regional Office, Seattle, WA

> Olesiuk PF, Nicol LM, Sowden MJ, Ford JB (2002) Effects of the sound generated by an acoustic harassment device on the relative abundance and distribution of harbour porpoises (Phocoena phocoena) in Retreat Passage, British Columbia. Mar Mamm Sci 18:843-862

> Pemberton D, Shaughnessy PD (1993) Interaction between seals and marine fish-farms in Tasmania, and management of the problem. Aquat Conserv Mar Freshwat Ecosys 3:149-158

Pilz PKD, Schnitzler HU (1996) Habituation and sensitization of the acoustic startle response in rats: amplitude, threshold, and latency measures. Neurobiol Learn Mem 66:67-79

Plomp R, Levelt JM (1965) Tonal consonance and critical bandwidth. J Acoust Soc 38:548-560

Pryor K (1987) Behavioural conditioning. In: Mate BR, Harvey JT (eds) Acoustical deterrents in marine mammal conflicts with fisheries. ORESU-W-86-001, Oregon State University Sea Grant College Program, Newport, OR, p 105-110

Quick NJ, Janik VM (2008) Whistle rates of wild bottlenose dolphins: influences of group size and behavior. J Comp Psychol 122:305-311

> Quick NJ, Middlemas SJ, Armstrong JD (2004) A survey of antipredator controls at marine salmon farms in Scotland. Aquaculture 230:169-180

Ramcharitar J, Popper AN (2004) Masked auditory thresholds in sciaenid fishes: a comparative study. J Acoust Soc Am 116:1687-1691

Reeves RR, Reed FA, Nortabartolo di Sciara G (2001) Report of the workshop on interactions between dolphins and fisheries in the Mediterranean: evaluation of mitigation alternatives. Istituto Centrale Per La Rocerca Scientifica E Tecnologca Al Mare (ICRAM), Rome

Reichmuth C, Southall BL (2012) Underwater hearing in California sea lions (Zalophus californianus): expansion and interpretation of existing data. Mar Mamm Sci 28: 358-363

Renaud DL, Popper AN (1975) Sound localization by the bottlenose dolphin Tursiops truncatus. J Exp Biol 63: 569-585

Richardson WJ, Greene CG, Malme CI, Thompson DH (1995) Marine mammals and noise. Academic Press, San Diego, CA

Rivinus A (1987) Oregon Aquafood's experience with a seal avoidance system. In Mate BR, Harvey JT (eds) Acoustical deterrents in marine mammal conflicts with fisheries. ORESU-W-86-001, Oregon State University Sea Grant College Program, Newport, OR, p 79-80

Ross A (1988) Controlling nature's predators on fish farms. Marine Conservation Society, Ross-on-Wye

Sadhra S, Jackson C, Ryder T, Brown M (2002) Noise exposure and hearing loss among student employees working in university entertainment venues. Ann Occup Hyg 46: 455-463

Schack HB, Malte H, Madsen PT (2008) The responses of Atlantic cod (Gadus morhua L.) to ultrasound-emitting predators: stress, behavioural changes or debilitation? J Exp Biol 211:2079-2086

Scharf B (1978) Loudness. In: Carterette EC, Friedman MP (eds) Handbook of perception Vol. IV: Hearing. Academic Press, New York, NY, p 187-234

Schlundt CE, Finneran JJ, Carder DA, Ridgway SH (2000) Temporary shift in masked hearing thresholds of bottlenose dolphins, Tursiops truncatus, and white whales, Delphinapterus leucas, after exposure to intense pure tones. J Acoust Soc Am 107:3496-3508

Schusterman RJ, Kastak D, Levenson DH, Reichmuth CJ, Southall BL (2000) Why pinnipeds don't echolocate. J Acoust Soc Am 107:2256-2264

Scottish Salmon Growers Association (1990) Salmon farming and predatory wildlife: a code of practice. Scottish Salmon Growers Association, Perth

Sepulveda M, Oliva D (2005) Interactions between South American sea lions Otaria flavescens (Shaw) and salmon farms in southern Chile. Aquacult Res 36:1062-1068 
Skinner BF (1969) Contingencies of reinforcement: a theoretical analysis. Appleton-Century-Crofts, New York, NY

Southall BL, Bowles AE, Ellison WT, Finneran JJ and others (2007) Marine mammal noise exposure criteria: initial scientific recommendations. Aquat Mamm 33(4)Spec Issue

Spreng M (1975) Physiological and psychophysical aspects of the threshold of discomfort and pain in hearing. J Audiol Tech 14:14-29

Stevens SS (1956) The direct estimation of sensory magnitudes-loudness. Am J Psychol 69:1-25

Stevens SS (1961) The psychophysics of sensory function. In: Rosenblith WA (ed) Sensory communication. Wiley, Oxford, p 1-33

Szymanski MD, Bain E, Kiehl K, Pennington S, Wong S, Henry KR (1999) Killer whale (Orcinus orca) hearing: auditory brainstem response and behavioral audiograms. J Acoust Soc Am 106:1134-1141

Taylor VJ, Johnston DW, Verboom WC (1997) Acoustic harassment device (AHD) use in the aquaculture industry and implications for marine mammals. Proc Inst Acoust 19:167-274

Terhune JM (1974) Directional hearing of a harbour seal in air and water. J Acoust Soc Am 56:1862-1865

Terhune JM (1988) Detection thresholds of a harbor seal to repeated underwater high-frequency, short-duration sinusoidal pulses. Can J Zool 66:1578-1582

Terhune JM, Hoover CL, Jacobs SR (2002) Potential detection and deterrence ranges by harbour seals of underwater acoustic harassment devices (AHD) in the Bay of Fundy, Canada. J World Aquacult Soc 33:176-183

Thompson DH, Fedak M (2001) How long should a dive last? A simple model of foraging decisions by breath-hold

Editorial responsibility: Peter Corkeron,

Woods Hole, Massachusetts, USA divers in a patchy environment. Anim Behav 61:287-296 van Parijs SM, Janik VM, Thompson PM (2000) Display area size, tenure and site fidelity in the aquatic mating male harbour seal. Can J Zool 78:2209-2217

> Vasconcelos RO, Amorim MCP, Ladich F (2007) Effects of ship noise on the detectability of communication signals in the Lusitanian toadfish. J Exp Biol 210:2104-2112

Vilata J, Oliva D, Sepulveda M (2010) The predation of farmed salmon by South American sea lions (Otaria flavescens) in southern Chile. ICES J Mar Sci 67: $475-482$

> Wardle CS, Carter TJ, Urquhart GG, Johnstone ADF, Ziolkowsk AM, Hampson G, Mackie D (2001) Effects of seismic air guns on marine fish. Cont Shelf Res 21: 1005-1027

Wilson M, Schack HB, Madsen PT, Surlykke A, Wahlberg M (2011) Directional escape behavior in allis shad (Alosa alosa) exposed to ultrasonic clicks mimicking an approaching toothed whale. J Exp Biol 214:22-29

Würsig B, Gailey GA (2002) Marine mammals and aquaculture: conflicts and potential resolutions. In: Stickney RR, McVey JP (eds) Responsible marine aquaculture. CAB International, Wallingford, p 45-59

Wysocki LE, Ladich F (2005) Hearing in fishes under noise conditions. J Assoc Otolaryng 6:28-36

Yurk H, Trites AW (2000) Experimental attempts to reduce predation by harbour seals on juvenile out-migrating salmonids. Trans Am Fish Soc 129:1360-1366

Zelick R, Mann DA, Popper AN (1999) Acoustic communication in fishes and frogs. In: Popper AN, Fay RR (eds) Comparative hearing: fish and amphibians. Springer Verlag, New York, NY, p 363-411

Zwicker E, Fastl H (1990) Psychoacoustics: facts and models. Springer Verlag, Berlin

Submitted: December 10, 2012; Accepted: July 13, 2013

Proofs received from author(s): October 23, 2013 